\title{
Nanomaterials and the Environment: Global impact of tiny materials
}

Raymond L.D. Whitby*

Rosa Busquets
Nanoscience \& Nanotechnology Group,

School of Pharmacy \& Biomolecular Sciences, University of Brighton, Lewes Road, Brighton, BN2 4GJ, United Kingdom

(c) Versita Sp. z o.o.

It is an honor to introduce this inaugural volume of the new open access journal Nanomaterials and the Environment (NATE). The association of nanomaterials with the environment is a rapidly emerging and often controversial area, and it is important to have a journal that brings together key developments in this expanding scientific and engineering field, which disseminates new ideas and technical advances to audiences across the globe.

Nanomaterials offer superior performance to their larger counterparts by scaling down the size of materials to a point where the surface atoms dominate the properties of the material or through a substantial increase in surface area. Whilst the early 1990s saw the explosion of nanomaterial research and development, natural nanomaterials have been present in society and nature for far longer. Though the exposure and impact of such nanomaterials on plant life and organisms is still under investigation, it is the contemporary, targeted large scale production and use of nanomaterials that represents a significant concern through nanomaterial release, migration, transformation and interaction with plants and organisms throughout the environment [1]. Through the implementation of responsible use of nanomaterials and extensive investigations of nanomaterial interaction with the environment, such risks can be mitigated or avoided, thus leaving the research community, industry and endusers to benefit from the use of nanotechnology.

Increasing interest has developed in the use of nanomaterials in a wide variety of environmental applications, including, but not limited to, wastewater, groundwater, soil and air purification [2-6], drug delivery in the environment [7,8], capture and storage or recycling of greenhouse gases, critical metals and chemicals [9-13], the development of barriers, filters and sensors [14-18]. This has led to a phenomenal number of publications, patents and nanotechnology-based devices with an environmental consideration and is occurring alongside the emergence of standardized testing criteria, which is helping to inform legislation.

The launching of NATE provides an exciting opportunity for a host journal that focuses specifically on environmental applications, implications, and other issues that link nanomaterials and the environment. This is a unique journal, with tremendous expected impact in the scientific literature and easy accessibility for scientists, stakeholders, and the public interested in the area of nanotechnology and nanomaterials. Exciting advances in open access publishing have rapidly unfolded as well, and we will take advantage of the best of these practices: rapid and transparent peer review; free access to readers around the world; indexing and database inclusion; low publication costs; and innovative dissemination through social media. The journal's advisory board has gathered a number of key academics in the field of nanoscience and the effect of nanomaterials in the environment, including Professor Sir Harold Kroto, 1996 Nobel Laureate in Chemistry for discovery of buckminster fullerenes (nanoscale all-carbon spheres).

Our first original research article in NATE comes from Prof. Sakthi Kumar of Toyo University in Japan. Kumar and coauthors demonstrate that the biological sources, seed shell and meal, which are the byproducts of Jatropha biodiesel industry, can be efficiently utilized for the synthesis of near uniform gold nanoparticles, thus providing a green, renewable source of a reduction chemical in the synthesis of high purity, high quality nanomaterials.

We hope readers will enjoy this first volume of NATE and look forward to receiving manuscript submissions from new authors. 


\section{References}

[1] Klaine, S. J.; Alvarez, P. J. J.; Batley, G. E.; Fernandes, T. F.; Handy, R. D.; Lyon, D. Y.; Mahendra, S.; McLaughlin, M. J.; Lead, J. R., Nanomaterials in the environment: Behavior, fate, bioavailability, and effects. Environmental Toxicology and Chemistry 2008, 27, 1825-1851.

[2] Pradeep, T.; Anshup, Noble metal nanoparticles for water purification: A critical review. Thin Solid Films 2009, 517, 6441-6478.

[3] Katok, K. V.; Whitby, R. L. D.; Fukuda, T.; Maekawa, T.; Bezverkhyy, I.; Mikhalovsky, S. V.; Cundy, A. B., Hyperstoichiometric interaction between silver and mercury at the nanoscale. Angewandte Chemie (International ed. in English) 2012, 51, 2632-5.

[4] Cundy, A. B.; Hopkinson, L.; Whitby, R. L. D., Use of ironbased technologies in contaminated land and groundwater remediation: A review. Science of the Total Environment 2008, 400, 42-51.

[5] Karn, B.; Kuiken, T.; Otto, M., Nanotechnology and in Situ Remediation: A Review of the Benefits and Potential Risks. Environmental Health Perspectives 2009, 117, 1823-1831.

[6] Kwon, S.; Fan, M.; Cooper, A. T.; Yang, H., Photocatalytic applications of micro- and $\mathrm{Nano}-\mathrm{TiO} 2$ in environmental engineering. Critical Reviews in Environmental Science and Technology 2008, 38, 197-226.

[7] Slowing, I. I.; Vivero-Escoto, J. L.; Wu, C.-W.; Lin, V. S. Y., Mesoporous silica nanoparticles as controlled release drug delivery and gene transfection carriers. Advanced Drug Delivery Reviews 2008, 60, 1278-1288.

[8] MaHam, A.; Tang, Z.; Wu, H.; Wang, J.; Lin, Y., ProteinBased Nanomedicine Platforms for Drug Delivery. Smal 2009, 5, 1706-1721.

[9] Lu, C.; Bai, H.; Wu, B.; Su, F.; Fen-Hwang, J., Comparative study of $\mathrm{CO}_{2}$ capture by carbon nanotubes, activated carbons, and zeolites. Energy \& Fuels 2008, 22, 3050-3056.

[10] Su, F.; Lu, C.; Cnen, W.; Bai, H.; Hwang, J. F., Capture of $\mathrm{CO} 2$ from flue gas via multiwalled carbon nanotubes. Science of the Total Environment 2009, 407, 3017-3023.

[11] Abughusa, A.; Amaratunga, L.; Mercier, L., The recovery of rhodium ions at ultra-low concentrations using nanostructured adsorbents. In Nanoporous Materials Iv, Sayari, A.; Jaroniec, M., Eds. 2005; Vol. 156, pp 957-962.

[12] Abughusa, A.; Amaratunga, L.; Mercier, L., Extraction of precious metal ions from simulated mine effluents using a nanostructured adsorbent. Canadian Metallurgical Quarterly 2006, 45, 237-241.

[13] Li, X.; Song, Q.; Liu, B.; Liu, C.; Wang, H.; Geng, J.; Chen, Z.; Liu, N.; Li, S., Adsorption of Uranium by Carbon Materials from Aqueous Solutions. Progress in Chemistry 2011, 23, 1446-1453.

[14] Guo, F.; Silverberg, G.; Bowers, S.; Kim, S.-P.; Datta, D.; Shenoy, V.; Hurt, R. H., Graphene-Based Environmental Barriers. Environmental Science \& Technology 2012, 46, 7717-7724.

[15] Zhang, L.; Fang, M., Nanomaterials in pollution trace detection and environmental improvement. Nano Today 2010, 5, 128-142.

[16] Turker, A. R., New sorbents for solid-phase extraction for metal enrichment. Clean-Soil Air Water 2007, 35, 548-557.

[17] Mauter, M. S.; Elimelech, M., Environmental applications of carbon-based nanomaterials. Environmental Science \& Technology 2008, 42, 5843-5859.

[18] Waggoner, P. S.; Craighead, H. G., Micro- and nanomechanical sensors for environmental, chemical, and biological detection. Lab on a Chip 2007, 7, 1238-1255. 